Accepted refereed manuscript of:

Rybaczewska M \& Sparks L (2020) Locally-owned convenience stores and the local economy. Journal of Retailing and Consumer Services, 52, Art. No.: 101939. DOI: https://doi.org/10.1016/j.jretconser.2019.101939

(c) 2019, Elsevier. Licensed under the Creative Commons Attribution-NonCommercialNoDerivatives 4.0 International http://creativecommons.org/licenses/by-nc-nd/4.0/

\title{
Locally-owned convenience stores and the local economy
}

Maria Rybaczewska, Marketing and Retail Division, Stirling Management School, University of Stirling, Research Fellow, FK9 4LA Scotland UK, maria.rybaczewska@stir.ac.uk, tel. +44 (0) 1786467384 (corresponding author)

University of Social Sciences (Społeczna Akademia Nauk), Assistant Professor, ul. Sienkiewicza 9, 90-113 Łódź, Poland

Leigh Sparks, Marketing and Retail Division, Stirling Management School, University of Stirling, Professor of Retail Studies, FK9 4LA Scotland UK, leigh.sparks@ stir.ac.uk

\begin{abstract}
:
The convenience store sector in the UK has been growing strongly in recent years. Anecdotal commentary and media coverage claims that locally-owned stores are more advantageous for community coherence and resilience, being embedded socially and economically more strongly (than chain stores) in their local community. This paper extends our understanding of this. Following a discussion of the literature on social and economic aspects of convenience store operation, a multi-stage mainly qualitative research process was undertaken. Using four case stores in Scotland, this research demonstrates the local engagement of locally owned convenience stores and points to a stronger awareness and detail of the economic rather than the social aspects of this engagement. Differences with corporately owned convenience stores are identified. In policy terms the research shows that more work needs to be done to identify, quantify and then promote the advantages of local ownership of stores.
\end{abstract}


Keywords: retailing, convenience stores, local ownership, social impact, economic impact.

\section{Locally - owned convenience stores and the local economy}

\section{Introduction}

The convenience store sector in the UK has been expanding in scale (there are now about 50,000 such stores) and importance (according to the Association of Convenience Stores, based on Retail Economics 2018 (UK data), in 2018: £8.8bn contribution in GVA and over $£ 3.6 \mathrm{bn}$ contribution in taxes). At a time of retail restructuring and changing consumer demands, the convenience sector has been one of the few 'bright spots' in UK retailing (Hood, Clarke \& Clarke 2016). The expansion of convenience stores has been attributed to meeting changing customer preferences, the enhanced variety of services and products offered and their locational alignment with work, travel and residence.

The convenience store has become a more important feature of retailing. At the same time there is an increasing concern over the role of large organisations and their impact on societies, economies and places. Local economies and the localisation of products and services are viewed as desirable with local (independent) stores as opposed to national corporate stores seen as better for the local society and economy.

Convenience stores are an operational format that can be operated by various organisational forms. Corporate convenience stores have expanded in the UK (Tesco Metro, Express etc.), but so too have affiliated and symbol groups (e.g. Spar, Premier). True, totally independent convenience stores have reduced in number as they have tended to affiliate to symbol groups to obtain benefits of sale. They remain though locally-owned in day to day operation. Locally owned stores (true independent and affiliated) operate in a wide spectrum of 
ways including their freedom to obtain local supply of products. It has been suggested that locally-owned convenience stores are playing a stronger role in both local economy and local society than previously and tend to have stronger and more extensive local links than for example corporate stores. The extent of this will vary from situation to situation.

There is a widespread view that communities with local businesses are more prosperous, united and entrepreneurial (e.g. Civic Economics 2012, McGee 2000). The terms 'local multiplier' (Sparks 2015) or 'community hub' (Pioch \& Byrom 2004) are often seen in the context of independent convenience stores and the benefits of 'being local'. This widespread view of the benefits of 'local' are translated into reasons for consumers to support locally owned businesses. Anecdotal reports and comments consistently emphasise both social and economic impacts of local stores but details are sparse and variable. There is a lack of consensus and a gap in knowledge over the role and contribution of local stores in and on the local economy.

It is also the case that there has been a focus on the direct economic relationships at the expense of a wider consideration of the social role of such locally-owned stores. As convenience stores have expanded so too their position has altered and it can be argued that locally-owned stores play a specific social as well as economic role in places. This research therefore considers the overall impact (both social and economic) of locally-owned convenience stores (Clarke \& Banga 2010). Our aim is to improve the understanding of the linkages and impacts of locally-owned convenience stores and specifically to answer research questions on the economic and social impact of locally-owned convenience stores on the local economy.

This paper comprises six main sections. This introduction is followed by a literature review focused on research on the impact of locally-owned convenience stores on the local economy, referring not only to their economic and social contribution but also the interdependencies between economic and social aspects. This section discusses the conceptual 
framework and the research questions. The following section provides the description of methods used to address the research questions. It is followed by the presentation of the results of the research. This leads to the conclusions and implications. The final section discusses the limitations of the research and suggests future research directions.

\section{Locally-owned Convenience Stores and the Local Economy: Conceptual Framework}

All retail outlets have an impact on local economies, but it can be suggested that locallyowned stores have an enhanced potential impact, and the more local they are in operation, the greater the local impact. The dimensions of this can be considered in turn for economic and social aspects. The structure for this is provided in Figure 1.

\subsection{Locally-owned convenience stores impact on the local economy-economic aspects}

It has been suggested that locally owned businesses help stimulate the local economy far more than multiple retailers as they spend more directly in the area where they operate (Paddison \& Calderwood 2007, Smith \& Sparks 2000), through their local business linkages. The 'multiplier effect' (Sparks, 2015) of local stores means that a far greater share of every pound spent in the local business circulates in the local economy (Civic Economics 2012, 2013). North American data has illustrated this; According to Civic Economics 2013 for every $\$ 1,000,000$ in sales, independent retail stores generate $\$ 450,000$ in local economic activity, compared to just $\$ 170,000$ for chains. For local restaurants the figures are $\$ 650,000$ for independents and $\$ 300,000$ for chains. Across both sectors this results in about 2.6 times as many local jobs created locally when spending is directed to independent businesses instead of chains. 
Martin and Patel (2011) analysed data collected from 28 locally-owned businesses in Portland together with some national chains and came to the conclusion that every $\$ 100$ spent at a locally-owned business contributes an additional $\$ 58$ to the local economy. By comparison, $\$ 100$ spent at a chain store in Portland yields just $\$ 33$ in local economic impact. They argue that if residents would shift $10 \%$ of their spending from chains to locally-owned businesses, it would generate $\$ 127$ million in additional local economic activity and 874 new jobs.

As outlined in Figure 1, it can be suggested that direct local spending on products and services by a locally-owned retailer can be more significant. This is due to their local linkages and to more of their spend being with local businesses. For example the local bakery may be used for local bread/cakes and the local accountant for the financial services needed. This local spend with local businesses thus sustains the local community. Spend on staff employed by the store is also retained in the locality. This is likely to be more so than for corporate chains where managers may be less local than owners of local stores. Finally it is likely that support for local charities and events also takes place from locally-owned stores.

The research to date has tended to be North American and focused on direct economic multipliers. This paper takes a broader approach and tries to address the following research question:

RQ1: What is the economic impact of independent convenience stores on the local economy?

\subsection{Locally-owned stores impact on the local economy - social aspects}

The social function of locally-owned shops is multidimensional and in part overlapping with local issues. They can be the only store available in the area, enabling (emergency) supply as well as being the focal point and source of specialist and local supplies (Smith \& Sparks 
2000). This social function also encompass a variety of social, sustainability and ethical needs (Megicks 2007). Locally-owned stores foster a sense of community and security, reduce isolation and support the independence of residents. The bond between business owners and the local community in which they operate has often been built over a long period of time. Such a long-term relationship frequently leads to the will and desire to serve the community instead of 'simply' running the business. According to the Association of Convenience Stores (ACS) and the Scottish Grocers Federation (SGF) $85 \%$ of independent retailers engaged in some form of community activity in the past year (The Scottish Local Shop Report (2018)). Various services offered by the convenience stores are appreciated by their customers. All these aspects become even more meaningful in the context of disadvantaged groups or groups with specific needs, including the elderly (e.g. Meneely, Strugnell \& Burns 2009), financially deprived, socially excluded (Broadbridge \& Parsons 2003) and less mobile (Schmidt, Jones, \& Oldfield 2005).

There is limited previous work on the more social and 'softer' side of locally-owned stores. It is often suggested anecdotally that they provide a community focus and stability to a location by their operation. The local nature of ownership enhances community links and can reduce isolation, both by visits to the store and interactions, but also in terms of supporting people at home when necessary. Relationships are core to this local service provision and to the notion of the locally-owned convenience store acting as a community hub. This leads us to our second research question:

RQ2: What is the social impact of independent convenience stores on the local economy?

This study underlines both economic and social impacts. The literature tends to focus on either the direct economic issues of local stores (often neglecting social and community aspects) or the social and community aspects (often neglecting economic issues). This research 
sets out to consider real examples from the practices of retailers in both the economic and social spheres of local stores.

\section{Methodology}

In order to address the two research questions, primary research with specific retailers is required. Aspects of the topic are sensitive (especially economic ones) with others tending to be developed on an intermittent and informal basis (eg. charity/event work). At the same time the context is important and the ways in which convenience stores and the sector are changing need consideration. Given the relative paucity of information the primary research consisted of three main stages (Figure 2), divided into two main dimensions (following Halbesleben and Tolbert (2014)):

a) the macro perspective revealing the tensions and constraints in the relationships between the locally-owned convenience stores and local communities at a general, sector level,

b) the micro perspective focused on individual experience of locally-owned stores. This stage provides the specific opinions about business reality and data on both social and economic aspects.

In order to obtain the detailed and specific access needed and to cover both dimensions, pre-existing contacts were mobilised to open up access to co-operating and interested retailers. Obtaining access was possible due to ongoing cooperation between the Scottish Grocers Federation and the University of Stirling. This meant that Scotland became the site for the research. There is no reason to suspect the outcomes would be different elsewhere in the UK, but this is considered further under limitations. Place specificity might affect the results more elsewhere e.g. Europe or the U.S. but the general trends are expected to be comparable. 
As shown in Figure 2, the first step was a focus group meeting attended by various stakeholder groups (SGF (2 people), retailers (4 people), specialist journalist (1 person)). The intention of the focus group was to use discussion amongst a group of experts and practitioners to scope the initial understanding of the issues and problems (e.g. Bryman \& Bell 2015), and identify the main concerns and issues from the stakeholders' perspective (e.g. Bill \& Olaison 2009). Additionally it aimed to schedule the next phase of the research, including the identification of the set of required business data and specific businesses in conjunction with potential retailers.

The focus group took place at the University of Stirling, moderated by both authors of this paper. It lasted over one hour and was recorded with notes taken by both authors. The group and notes were transcribed and then analysed by both authors seeking thematic components. Separate consideration was undertaken before comparison and discussion to finalise themes.

The participants were identified between the authors and the Scottish Grocers Federation. They comprised the leaders of the SGF, a key independent journalist for the sector (who also runs a store) and four selected retailers who had expressed an interest in this subject. This selection is discussed later under limitations but is a trade-off with availability.

The second stage (Figure 2) focused on the macro-scale dimension. Semi- structured face-to-face interviews with the SGF and the trade magazine journalist were conducted (3 participants) to provide expert evidence on trends in the sector and stores. This phase was focused on the analysis of research questions from the long-term perspective and the interdependencies between economic and social impacts of locally-owned convenience stores at a sector level. The aim was to reveal the background environment and conditions for the specific retailers.

These interviews were with people who had been in the focus group and sought a more developed and in-depth conversations. Each interview lasted circa 45 minutes, was voice 
recorded and transcribed. The interviewer, one of the authors, took additional exploratory notes. Transcripts were analysed using Miles and Huberman's (1994) reduction logic and matrix approach. Key themes were created on both secondary data and from the focus group.

The third stage concentrated on the micro, individual experience of the selected case stores in Scotland. This was a key stage to answer the research questions using experiences of practitioners. Despite limitations of case studies (e.g. Flyvbjerg 2006), they were chosen here as an effective methodology in terms of studying the phenomenon within the specific context (see also Stake (2005) and Yin (2013)). It is also the only practical method combining multiple sources of information leading to the in-depth exploration and understanding of the complex real-life phenomena (Gerring 2006). Four cases were selected enabling:

a) variety of location (one in a large city - Edinburgh, two in the suburbs of Glasgow, one in a smaller Scottish town - Falkirk),

b) strong managerial and background knowledge of the chosen retailers indispensable to achieve the study's goals (SGF recommendations for cases),

c) feasibility - openness to contribute by revealing sensitive business data.

The case study design incorporated both qualitative and quantitative elements i.e. semistructured interviews with the store owners and key managers (7 interviewees), photographic and document analysis (Figure 3). All interviews were conducted face to face, lasted around 45 minutes, were voice recorded, transcribed and analysed using Miles and Huberman's (1994) as before. Every interviewee was provided all the details about the research project at the beginning of the interview (not all the interviewees had participated in the focus group meeting). The key themes created following the secondary sources (literature) and the focus group and prior interviews were used to structure the discussion. Themes covered awareness of local issues among the businesses and customers, understanding the term 'local' in this context, real-life business functioning (from the perspective of the most meaningful challenges and 
opportunities) and initiatives undertaken addressing local issues, all combined into the overall social and economic influence of locally-owned convenience stores on the local community. Photographic investigation was conducted from the perspective of the messages provided for the customers through the offer quality and the customer experience in the store. Attention was paid to local aspects (any visual elements emphasising the presence/offer of local products/brands/suppliers/manufacturers or proving some local activities engagement of the businesses or encouraging the customers to undertake some activities supporting local community etc.). Quantitative analysis was conducted in close cooperation with the retailers, enabling the proper understanding of the data and standardization to achieve cross-cutting analysis. Data obtained covered various sensitive business data including accounting records concerning cost evidences, invoices etc., HRM records revealing the specific information from job-contracts of current staff (full-time versus part time, salary details etc.), tax obligations, fixed and variable costs of business every-day functioning, investments (both conducted and planned) etc. All figures were contextualised with the personal notes of business managers and information gathered from them by the researcher. The overall goal of this phase analysis was to identify the distinction between the local and non-local components.

The choice of case stores was driven by the availability of engaged retailers and it is acknowledged that they are not a representative sample (they are not intended as such). The stores are however broadly typical locally-owned convenience stores in the central belt of Scotland. The data provided by the respondents was non-standardised and often in very different formats making accurate, standardised quantitative analysis very difficult. The photographic evidence proved to be generic on store layout with some aspects of local information. It provided incomplete/insufficient to use in formal analysis, though did inform the approach taken. 


\section{Findings and Discussion}

The results from the research are presented in three main ways. First we consider the broad themes arising from the focus groups and the interviews. Then we consider the economic and social aspects under two headings, the macro and then the micro perspective.

The focus group reinforced that the convenience stores sector is an important part of the Scottish retail, economic and social 'landscape' and the sector's role is meaningful, especially from the perspective of local economy and society. This changing and enhanced role promoted the need for further investigation of the sector and was a motivation for the willingness to contribute to the research. The need for more open discussions, widening the awareness of the role of locally-owned convenience stores in the local economy and among local communities and consumers in general was emphasised. Communication of the aspects of localisation of locally-owned convenience stores was consistently perceived as not strong enough and the lack of a clear message of the interdependencies between local businesses, communities and economies was stressed. Locally-owned stores were believed to be more 'local' but the evidence for an articulation of this was underdeveloped.

The focus group revealed also the awareness of a distinction between the economic and social aspects that should be taken into consideration while addressing the issue of the locallyowned convenience stores sector. There was a view that neither economic nor social operations and benefits were clearly enough identified or quantified. All participants underlined the mutual relationships between these aspects i.e. locally-owned stores provided both economic and social advantages.

In order to understand the scale of economic and social operations, details of sensitive data would need to be available. All participants underlined the fact that the access to such business data is indispensable, but acknowledged the possible challenges connected with it. 
These are primarily the lack of openness to share any financial records with the researchers (e.g. the competitive advantage of particular businesses) and thus the need for data security and confidentiality, but also the recognition that different independent businesses keep records and data in different ways. At a general level, the retailers were able to categorise the largest costs in their business distinguishing the main local and non-local components among them, but moving beyond the general could prove difficult.

\subsection{Macro perspective on the impact of locally-owned convenience stores on the local economy}

Our respondents indicated that it is more difficult to run a successful independent convenience store now than it was a couple of years ago. The key reasons were not competition (which they treat as a natural challenge every business must face) but laws and regulations, for example those affecting staff costs (Minimum National Wage and Minimum Living Wage), training and licenses ('you need to spend more and more on this and don't get anything extra'), and additional duties e.g. recycling which enlarge the workload and cost base.

Interviewees emphasise that for locally-owned retailers their business means far more than simply the source of profits. This sector is based around on family-owned businesses and for them it is more about life style. They value their existence in their community, often over a very long time. They are committed to the concept of keeping money local and being as beneficial as possible for the place and people. They are determined to invest in that community, to cooperate with locals and to promote local products. Even if they define 'local' differently, they all support the general concept and try to be as dedicated to the local community as possible.

Themes concerning the awareness and understanding of local issues revealed that among the retailers there is a strong consciousness of the local aspects of their business but 
often limited specific detail. Perceiving the locally-owned convenience shop as the 'hub' for the local community is common, but with little definition or detail beyond that. Locally-owned retailers feel a part of their community, and that it is their intrinsic obligation to get involved in that community. This results from their internal motivation, not an external, business one. It was also emphasised that whilst all social activities are mutual and positively affect the organisation, it is not about public relations or profits. For independent retailers it is far more about giving something back to the community which they know (very often for many years, sometimes generations), respect and treat as the main driver of their business. Moreover, they see it as their responsibility to the community in terms of staff, sustainability, education and access to proper services. The respondents care about future generations; they organise breakfast clubs, they cooperate with schools and nurseries e.g. to show children how to eat healthy. They also have very individual approaches to every customer. They treat customer service as one of the most powerful sources of their competitive advantage.

In social terms therefore the retailers at a macro-level recognise the broad parameters of local engagement but often struggled to articulate a comprehensive approach. This perhaps reflects the local nature of activities and occasionally its sometimes ad-hoc aspects.

Locally-owned retailers are increasingly sensitive to the local issues in terms of the choice of local suppliers and products. Interviewees perceive local supply and production as a long-term goal although they underline that 'immediate actions should be undertaken'. Currently, 'whenever the retailers need something, their first reaction is to look for these products and services locally'. For the local economy it matters that almost all of the locallyowned convenience store employees are local. Almost all of the services required were also locally sourced. The vast majority of money spent by the locally-owned convenience stores on labour and services is directed to local firms and people. 
In terms of figure 1 therefore, at a macro level the respondents focused on all of the economic components identified. There were clearly of significance to them, though support for local charities and events was less consistent. The social elements were broadly recognised but with less clarity and certainty. The focus on acting as a 'hub' for the community was prevalent but rather undefined, and certainty unmeasured.

\subsection{Micro perspective on the impact of locally-owned convenience stores on the local economy}

We can examine these aspects in more detail by reference to the specific cases. Whilst the four cases are different and details varied (Figure 3), many shared thoughts and patterns of actions and spend. All the retailers define customers as local since they are living in the very close neighbourhood of the store. At the same time they understand the radius for suppliers as much bigger. Local in that sense means the city, region or sometimes country, when it is about products labelled 'made in Scotland'. All participants agree, though, that the closer the better, so they concentrate on the closest area. As noted above, the themes of 'hub' of the community and being the 'heart of the community' are readily articulated by the retailers. Community and 'local' are understood and defined differently amongst them though.

The case studies revealed that if the locally-owned convenience stores do not explicitly concentrate on the relationship between them and the local community, it is because they unconsciously feel part of their community and are naturally involved ('I am not the owner of this business, my community is'). Themes referring to the immeasurable aspects showed that retailers feel responsible for the community and their customers are seen as members of their family (most obviously the long-term and loyal ones). The relationship has been built over many years and it is connected with high commitment and trust ('some customers ask for help when they are alone home, some give us their PIN numbers to their credit or debit cards' etc.). 
Such bonds matter especially in the context of disadvantaged people functioning in the community (e.g. Meneely, Strugnell \& Burns 2009). Openness to helping locally is the main driver of various charity activities undertaken by the independent retailers (educational projects increasing awareness of healthy food and eating habits; breakfast clubs; local projects support in the form of free food delivery etc.). Sometimes it is also about helping a particular customer in need. According to the interviewees this is a unique mission that nobody else would undertake, if not the locally-owned convenience retailers. This is perceived as a differentiation to the chain convenience stores.

Services offered by the locally-owned convenience stores (payment services, parcels, post offices etc.) are sometimes almost non-profit activities but offered in order to be the 'hub' for the community. Such an attitude corresponds with their priorities of relationship building (Pioch \& Byrom 2004), information sharing, creating emotional connections in a friendly atmosphere (Baron et al. 2001) and community building in general (Alexander 2008, Wallis 2008). This is mainly, though, about community involvement, responsibility for its condition and sustainability ('Sometimes even pubs are closed, if we are next what stays here?'). According to the ACS and SGF such services are highly valued by the customers (The Scottish Local Shop Report (2018)). This social element can thus be more clearly understood at the level of the individual store.

The localisation of the stores was evident photographically. The stores in the sample are modern, well organised, with services being added on a consistent basis (e.g. coffee vending and food to go). The local servicing and provenance of products were highlighted in each of the stores. There was also visual evidence of local community engagement (e.g. certificates, posters etc.) both of a short-term and long-term natures. The details of these varied but the sense of a 'hub' was prevalent. 
All respondents focused on the fact that their main but totally local cost is that of staff. It is important for them that $100 \%$ of their staff are local people which maximises both the money staying in the local community and the knowledge of the area/community. Around $90 \%$ of services used by the retailers are local, so money spent on them stays (more likely) in the local community. All case studies showed that the first reaction of the retailers, if anything is needed, is to check in their community. When their needs can be fulfilled by local providers they usually choose these options (as suggested by the interviewees, the only justification not to do so was an unreasonable offer). Consequently, the vast majority of services are provided locally.

Exact figures describing proportion of local products offered are different for each case but the general trend is that the share of local products is increasing (as identified by all retailers). According to the data from the retailers, it can be stated that local spend currently is around $15 \%$ of the whole spend on products. Among the local bestsellers the retailers mention: meat from the local butcher, bread, milk, daily fresh food, flowers etc. Differentiation between local and non-local providers in Figure 4 is done on the basis of average results for the four retailers. The figure shows that the retailers focus spend locally where available.

Spend on local project involvement (e.g. charity, events, sponsorships) also differs in each case study but, according to the data, the retailers spend about $10 \%$ of their turnover on such activities. This claim could not be verified, though they emphasise that its relation to their net profit is far higher. They also claimed they try to increase this figure each year, but it is dependent on the situation in the community and its needs.

\section{Conclusions and Implications}


This paper aimed to investigate the social and economic aspects of the operation of locally-owned convenience stores. Through focus group and interviews and then four case study stores, we explore the scale and scope of locally-owned convenience store engagement in these social and economic aspects of operations.

The findings of this work at one level broadly confirm previous commentaries. It is difficult to gain exact data on spend, both in absolute terms and because retailers differ in their categorisation and recording of this, but the general approach was consistent. Economic components, such as spend on staff, services and products are local where possible, and especially in the former two categories. There is an evidence base for localisation of activities and circulation of money locally. Social components were harder to pin down, beyond a general reflection of a role as a community 'hub'. The case details did provide examples, but they are not consistent, being highly locally dependent. There is a sense that operations are not as clearly valued and thought out in social as opposed to economic terms.

We conclude that the relationships between locally-owned convenience store and the local economy reflects mutual interdependencies. First, to make such locally-owned businesses function in the market, the customers have to be convinced to shop there. Their attitude could be more positive if they get easy access to trustworthy information on the locally-owned convenience stores involvement in the local community. Secondly, the growth of independent stores would affect their capacity, ability and willingness to contribute to the local community. It can also strongly affect the amount of money circulating in the local economy. Locally-owned retailers feel underestimated which, according to them, results from not speaking with one clear voice about their local benefits. All the respondents suggest that currently the communication is done far better by the chains, even if the genuine involvement and contribution to the local economy is the domain of locally-owned convenience stores. This may also be a reflection of true local operations and their disparate nature as opposed to corporate planned initiatives. 


\section{Limitations and Future Research}

There are a number of limitations of this research. The study requires access to confidential and sensitive business data. Both access and categorisation of spend are problematic. The data access obtained for this paper suggested the potential for future investigation but the need for the development of a standard categorisation, which will require further work, probably recategorisation, and considerable time and effort. Obtaining access was paramount but does raise an issue about the representativeness of the sample. Willing retail volunteers may not be completely reflective of the population, but in this case we believe they provide appropriate examples of the subject and the scale and scope of economic and social local operations.

Future research could thus focus on widening the analysis by extending the quantitative work. Access to further and more in-depth data is required; this can be complicated and timeconsuming for the retailers. Further research will be based on widening the sample and building a model to quantify the economic impact of locally-owned convenience stores on the local economy. However this should not be analysed separately from the social aspects since they interact and the social aspect remains a key differentiation. For this reason locally focused consumer research is also required.

If it was possible, then a sample that included some corporate convenience stores could address directly the differences between corporately-owned and locally-owned convenience stores. Locally-owned stores emphasise their social role and argue that this is not replicable to the same extent by corporate stores. Similarly economic impacts are claimed to be more locally extensive. Our paper provides some support for this, but from one side of the discussion; it would be good to test this more generally. 


\section{References}

ACS The Scottish Local Shop Report 2018 (2018) Retrieved from https://www.scottishshop.org.uk/publications (Last accessed: April 2, 2019).

Alexander, A. (2008) Format development and retail change: Supermarket retailing and the London co-operative society. Business History, 50 (4), pp. 489-508.

Baron, S., Harris, K., Leaver, D. \& Oldfield, B. M. (2001) Beyond convenience: the future for independent food and grocery retailers in the UK. The International Review of Retail, Distribution and Consumer Research, 11 (4), pp. 395-414.

Bill, F. \& Olaison, L. (2009) The indirect approach of semi-focused groups: expanding focus group research through role-playing. Qualitative Research in Organizations and Management: An International Journal, 4 (1), pp. 7-26.

Broadbridge, A. \& Parsons, L. (2003) Still serving the community? The professionalisation of the UK charity retail sector. International Journal of Retail \& Distribution Management, 31 (8), pp. 418.

Bryman, A. \& Bell, E. (2015). Business research methods: Oxford University Press, USA.

Civic Economics (2012) Indie Impact Study Series: Salt Lake City, Utah. Retrieved from http://www.localfirst.org/images/stories/SLC-Final-Impact-Study-Series.pdf. (Last accessed: February 14, 2019).

Civic Economics (2013) Independent BC: Small Business and the British Columbia Economy. Retrieved from http://nebula.wsimg.com/31f003d5633c543438ef0a5ca8e8289f?AccessKeyId=8E410A17553 441C49302\&disposition=0\&alloworigin=1. (Last accessed: December 3, 2018). 
Clarke, I. \& Banga, S. (2010). The economic and social role of small stores: a review of UK evidence. The International Review of Retail, Distribution and Consumer Research, 20 (2), pp. 187-215.

Flyvbjerg, B. (2006) Five misunderstandings about case-study research. Qualitative inquiry, 12 (2), pp. 219-245.

Gerring, J. (2006) Case study research: Principles and practices. Cambridge University Press.

Halbesleben, K. L. \& Tolbert, C. M. (2014) Small, local, and loyal: How firm attributes affect workers' organizational commitment. Local economy, 29 (8), pp. 795-809.

Hood, N., Clarke, G. \& Clarke, M. (2016) Segmenting the growing UK convenience store market for retail location planning. The International Review of Retail, Distribution and Consumer Research, 26 (2), pp. 113-136.

Martin, G. \& Patel, A. (2011) Going Local: Quantifying the Economic Impacts of Buying from Locally Owned Businesses in Portland, Maine.” Retrieved from http://www.mecep.org/wp-content/uploads/2011/12/MECEP_Report_-_Buying_Local-12-52011.pdf (Last accessed: January 10, 2019).

McGee, J.E. (2000) Toward the development of measures of distinctive competencies among small independent retailers. Journal of Small Business Management, 38 (2), pp. 20002033.

Megicks, P. (2007) Levels of strategy and performance in UK small retail businesses. Management Decision, 45 (3), pp. 484-502.

Meneely, L., Strugnell, C. \& Burns, A. (2009) Elderly consumers and their food store experiences. Journal of Retailing and Consumer Services, 16 (6), pp. 458-465.

Miles, M. B., \& Huberman, A. M. (1994). Qualitative data analysis: An expanded sourcebook: Sage Publications. 
Paddison, A. \& Calderwood, E. (2007). Rural retailing: a sector in decline?

International Journal of Retail \& Distribution Management, 35 (2), pp. 136-155.

Pioch, E. \& Byrom, J. (2004) Small independent retail firms and locational decisionmaking: Outdoor leisure retailing by the crags. Journal of Small Business and Enterprise Development, 11 (2), pp. 222-233.

Schmidt, R.Â., Jones, P. \& Oldfield, B. M. (2005) Implementing the disability discrimination act 1995: A comparison of Manchester city centre and out-of town retailer responses. International Journal of Retail \& Distribution Management, 33 (9), pp. 669-684.

Smith, A. \& Sparks, L. (2000) The independent small shop in Scotland: A discussion of roles and problems. Scottish Geographical Journal, 116 (1), pp. 41-58.

Sparks, L. (2015) Local Convenience Stores in a Challenging Retail Environment. Retrieved from https://stirlingretail.com/2015/03/31/local-convenience-stores-in-achallenging-retail-environment/ (Last accessed: December 5, 2018).

Stake, R. (2005) Qualitative case studies. In N. Denzin \& Y. Lincoln (Eds.), The sage handbook of qualitative research. Thousand Oaks, CA: Sage Publications.

Wallis, P. (2008) Consumption, retailing, and medicine in early-modern London. Economic History Review, 61 (1), pp. 26-53.

Yin, R. K. (2013) Case study research: Design and methods. Sage Publications. 
Figure 1. Conceptual framework

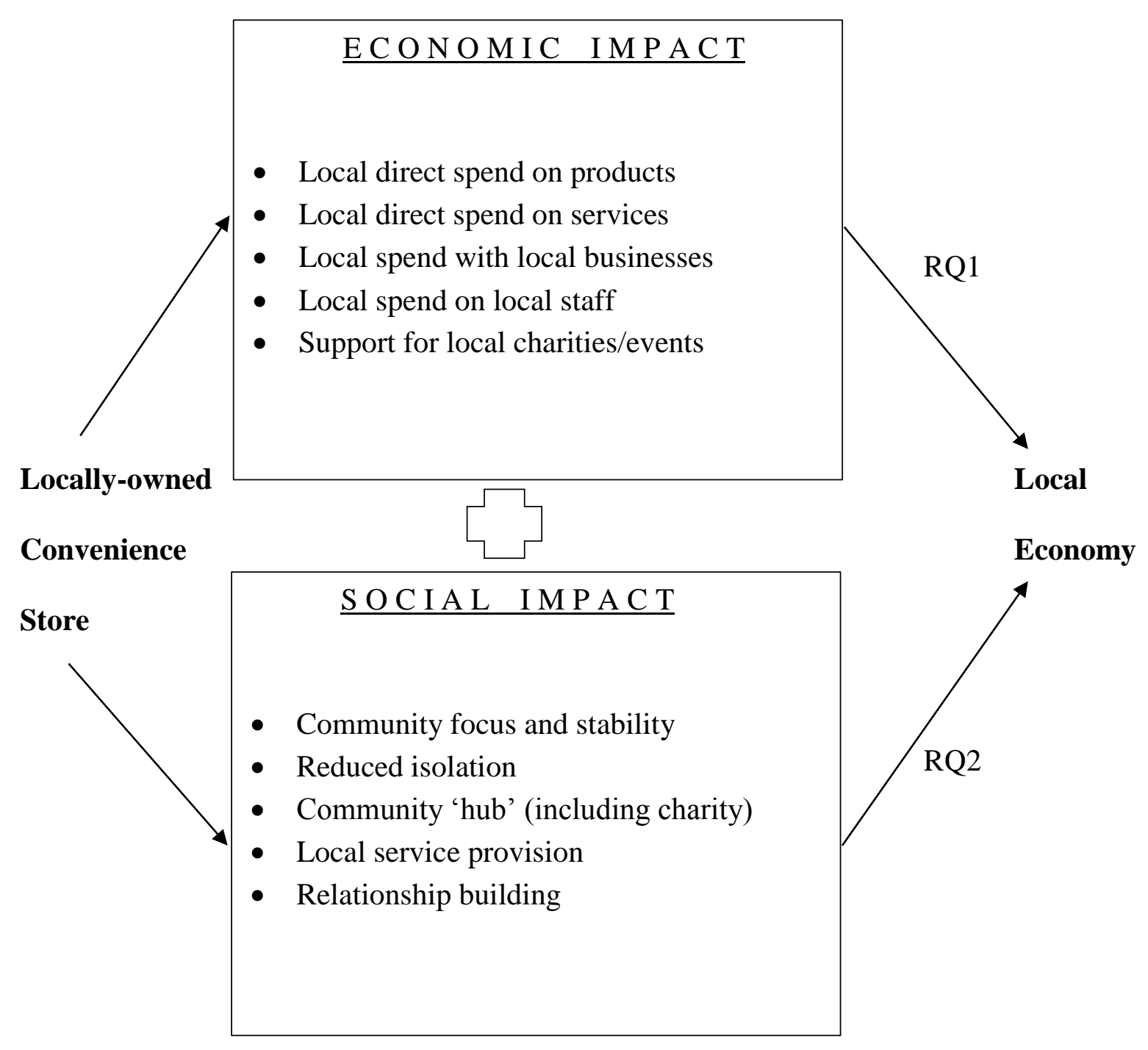


Figure 2. Research procedure

\section{OVERA L L P I T T RE}

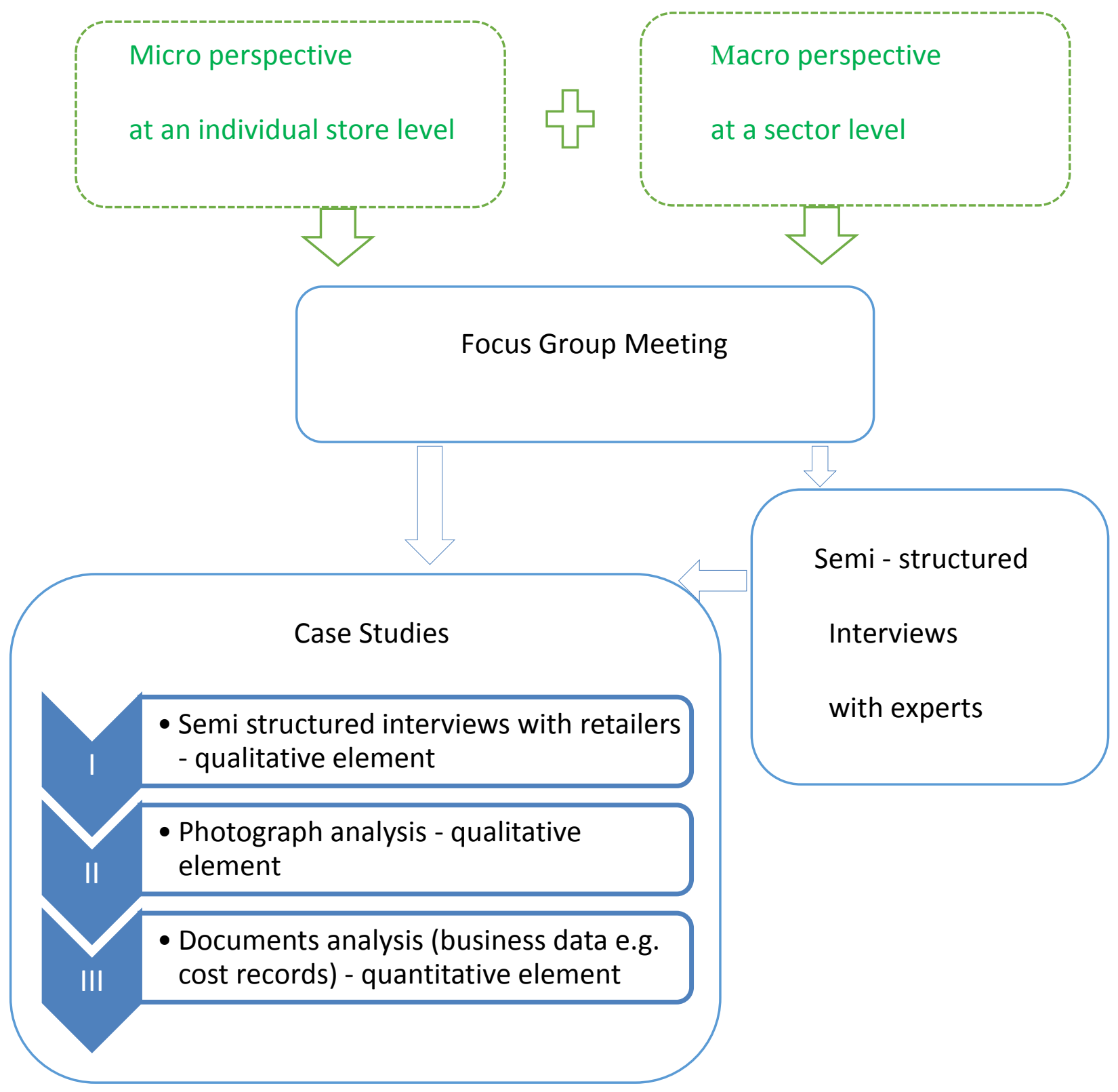


Figure 3. Case studies - summary.

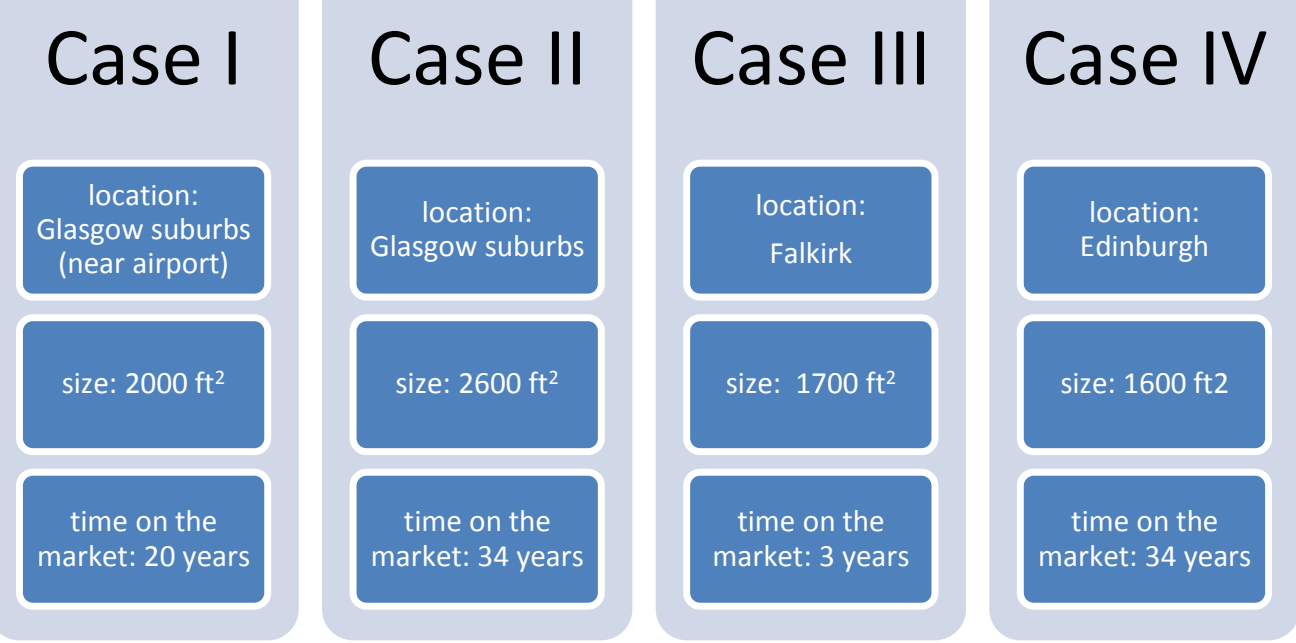


Figure 4. Main groups of services used by the independent convenience stores.

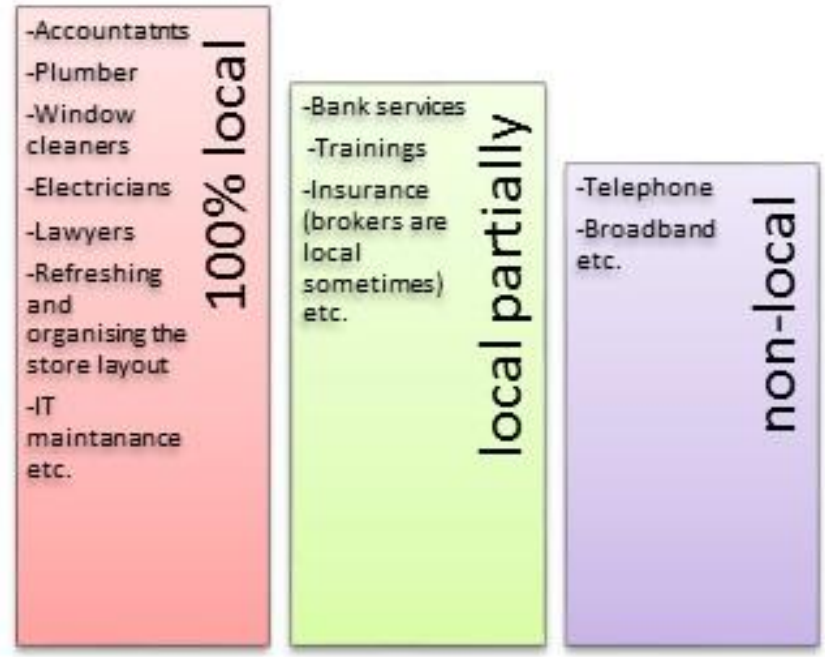




\section{Acknowledgements}

We would like to thank Dr Pete Cheema, Chief Executive of the Scottish Grocers' Federation for his assistance in identifying retailers to collaborate in the research and to those retailers for their willingness and openness to respond to our questions. 